\title{
Refractory Osteosarcoma
}

National Cancer Institute

\section{Source}

National Cancer Institute. Refractory Osteosarcoma. NCI Thesaurus. Code C142857.

Osteosarcoma that does not respond to treatment. 